\title{
Large-scale atmospheric flow conditions and sea surface temperatures associated with hazardous winds in Switzerland
}

\author{
Christoph Welker • Olivia Martius
}

Received: 27 November 2013 / Accepted: 6 November 2014 / Published online: 25 November 2014

(C) Springer-Verlag Berlin Heidelberg 2014

\begin{abstract}
The link between hazardous winter winds in Switzerland and the large-scale atmospheric and sea surface temperature (SST) environment in the North Atlantic basin is examined. The analyses cover synoptic, interannual, and decadal time scales and are based on all ensemble members of the Twentieth Century Reanalysis dataset for 1871-2008. On the synoptic time scale, the top ten high wind events in Switzerland are analysed; on longer time scales, the variability of the integrated winter wind loss potential (WLP) in Switzerland is examined. The top ten high wind events were associated with an eastward extension of the extratropical jet, enhanced cyclone frequencies over the North Sea and Scandinavia and reduced cyclone frequencies over the Mediterranean. The events were further accompanied by positive SST anomalies in the East Atlantic and the Mediterranean, and positive lower-tropospheric temperature and atmospheric moisture anomalies over Western and Central Europe. On interannual and decadal time scales, the winter WLP variability was associated with a large-scale atmospheric and SST pattern resembling a southeastward displacement of the winter North Atlantic Oscillation (NAO) pattern. The correlation of the WLP with the NAO and the East Atlantic pattern was positive for most of the 1951-2008 period, and increased with time. The distinct eastward shift of the northern centre of action of the NAO at the end of the twentieth century may explain the improved correlation between the winter NAO variability and the WLP.
\end{abstract}

C. Welker $(\bowtie) \cdot$ O. Martius

Oeschger Centre for Climate Change Research and Institute of Geography, University of Bern, Hallerstrasse 12, 3012 Bern, Switzerland

e-mail: christoph.welker@giub.unibe.ch
Keywords Variability of winter storms over Switzerland · Large-scale atmospheric and SST environment - NAO . Teleconnection patterns $\cdot 20 \mathrm{CR} \cdot$ Objective cyclone detection

\section{Introduction}

Severe winter storms are among the most destructive meteorological hazards in Central Europe. Very intense winter storms such as "Lothar" (December 1999; e.g., Wernli et al. 2002) or "Kyrill" (January 2007; Fink et al. 2009) affect large areas and cause fatalities and widespread damage. European winter storms resulted in total insured losses of about 50 bn US\$ in 1970-2006 (Schwierz et al. 2010). In Switzerland, approximately $28 \%$ of the total damages to property from natural hazards between 1991 and 2010 were due to storms (Imhof 2011).

Detailed analyses of individual recent, severe winter storm events in Switzerland showed that these storms formed in specific large-scale flow environments (e.g., Wernli et al. 2002; Fink et al. 2009). The following largescale flow conditions were typically associated with the occurrence of strong windstorms that affected Switzerland. (1) A straight, strong jet over the North Atlantic (NA) is generally conducive to the occurrence of windstorms over Central Europe (Schüepp et al. 1994). In addition, the latitudinal position of the jet is important, as a central position of the jet stream over the NA increases the odds of high-wind events in Switzerland (Mahlstein et al. 2012). This central position of the jet is associated with a neutral

\footnotetext{
${ }^{1}$ In this work, all storm names are as used by the German Weather Service.
} 
to positive phase of the North Atlantic Oscillation (NAO) and a neutral to positive phase of the East Atlantic pattern (EA) (Woollings et al. 2010). (2) At the surface, synoptic weather situations concomitant with high wind speeds in northern Switzerland are often characterised by a strong pressure gradient over Central Europe, with a deep low pressure system located over Northern Europe, and the formation of a secondary low that moves into the pre-existing pressure gradient over Central Europe (Schüepp et al. 1994; Fink et al. 2009). These secondary low pressure systems typically form in the left exit area of the strong NA jet. (3) Positive sea surface temperature (SST) anomalies in the central NA played a crucial role in the formation and strengthening of the very intense winter storm "Lothar" (Wernli et al. 2002; Goyette 2011). The poleward transport of warm, moist air masses from the tropics and subtropics and the associated increase in the release of latent heat by extratropical cyclones can result in significant cyclone intensification (e.g., Fink et al. 2012).

Hazardous winter winds in northern Switzerland identified in the Twentieth Century Reanalysis (20CR) dataset (Compo et al. 2011) and in independent wind speed measurements exhibited a pronounced interannual and decadal variability since the end of the nineteenth century (Welker and Martius 2013). The decadal variability has periods between approximately 36 and 47 years. At these decadal periodicities, the variability of hazardous winter winds in northern Switzerland was positively correlated with the winter NAO variability. The strength and statistical significance of this co-variability was non-stationary and the low-frequency winter NAO variability was leading the lowfrequency hazardous winter wind variability in northern Switzerland by approximately 5 years. The former finding is in agreement with Matulla et al. (2008), who estimated geostrophic wind speeds in Europe in the late nineteenth and twentieth centuries using historic surface pressure readings, and who emphasised that the NAO index's ability to explain European "storminess" varied with time and across regions. The ambiguous signal for Switzerland is related to the fact that Switzerland is situated at the intersection of the NAO nodal lines. To the north and to the south of Switzerland, the frequency of winter storms has most prominently been modulated by the NAO (e.g., Raible 2007; Pinto et al. 2009; Nissen et al. 2010). For example, most of the winter storm days in Germany between 1961 and 2000 occurred during the positive phase of the NAO (Donat et al. 2010). By contrast, positive NAO phases were generally associated with a decrease in the frequency of winter storms over the western Mediterranean region in 1957-2002 (Nissen et al. 2010). Because Switzerland is located between these regions, it is an open question to what extent and how the NAO modulates the frequency of winter storms in Switzerland.
In summary, our current knowledge regarding the largescale atmospheric and SST conditions that accompany the occurrence of hazardous winter storms in Switzerland is mainly based on detailed analyses of few recent, severe winter storm events. Using the novel 20CR dataset, it is possible to corroborate and extend these findings to a larger storm sample, including historic windstorms. Furthermore, the 20CR allows investigating the processes that govern the variability of winter storms over Switzerland on interannual and decadal time scales, which are so far poorly understood. It is important to further our understanding of the processes that govern the variability of winter storms over Switzerland in order to improve seasonal to decadal predictions and to assess if the variability patterns are influenced by anthropogenic climate change.

Hence, based on atmospheric reanalysis data from the 20CR and SST data from the Hadley Centre Sea Ice and SST (HadISST) dataset (Rayner et al. 2003) we aim to address the following questions:

1. What are the large-scale atmospheric flow and SST conditions associated with hazardous winter winds in Switzerland during the last 140 years on synoptic, interannual, and decadal time scales?

2. What is the link between large-scale teleconnection patterns over the North Atlantic and Eurasia and the variability in hazardous winter winds in Switzerland?

\section{Data}

Our investigations are based on the global 20CR ensemble dataset (Compo et al. 2011) and the global HadISST dataset (Rayner et al. 2003) for the period 1871-2008. The 20CR ensemble of 56 members currently spans 1871-2012 and the data are available every $6 \mathrm{~h}$ on a $2^{\circ} \times 2^{\circ}$ latitudelongitude grid (interpolated from a spectral grid). Considering the whole 20CR ensemble (rather than only the ensemble mean) allows us to give an uncertainty estimation for our findings. Monthly SST and sea ice fields from the HadISST dataset are available in $1^{\circ}$ area grids for the period 1870 -present. This dataset was used to set the boundary conditions for the computation of the 20CR.

To examine the relationship between hazardous winter winds in Switzerland and the large-scale atmospheric circulation, we use (1) the station-based December to March (DJFM) NAO index (Hurrell 1995) from 1864 to present and (2) monthly indices of teleconnection patterns over the NA and Eurasia dating back to 1950 from the Climate Prediction Center (CPC) based on the rotated principal component analysis (RPCA) technique used by Barnston and Livezey (1987). We use only those NA and Eurasian teleconnection patterns that are considered physically relevant 
according to Franzke and Feldstein (2005). These patterns are the NAO, EA, East Atlantic/West Russia pattern (EA/WR), and the Scandinavia pattern (SCA). Barnston and Livezey (1987) called the EA/WR "Eurasian pattern Type 2" and the SCA "Eurasian pattern Type 1". For each of the indices, seasonal means for all extended winter seasons (DJFM) in 1951-2008 are computed.

\section{Methods}

\subsection{Wind loss potential}

A simple measure is used to quantify the local loss potential associated with high wind speeds, referred to as wind loss potential (WLP) (see Welker and Martius 2013 for details). The winter WLP is computed by summing the cubes of the wind speeds that exceed the loss-relevant, local annual 98th percentile of the wind speed (see also Klawa and Ulbrich 2003; Emanuel 2005). We calculate the WLP using near-surface (0.995-sigma level) wind speeds at 6-hourly intervals from the 20CR ensemble. By using the local annual 98th percentiles of wind speed, the adaption of buildings, infrastructure, forest, etc. to local wind conditions is taken into account. The WLP is summed over the 20CR Switzerland grid cells $\left(6^{\circ} \mathrm{E}-10^{\circ} \mathrm{E}, 46^{\circ} \mathrm{N}-48^{\circ} \mathrm{N}\right)$ for each extended winter season (DJFM) in 1872-2008 and for each 20CR ensemble member.

\subsection{Objective surface cyclone identification}

We apply the objective cyclone identification scheme of Wernli and Schwierz (2006) to the global mean sea level pressure (MSLP) data of each of the 20CR ensemble members. A cyclone is defined as the finite area that surrounds a local MSLP minimum bounded by a closed MSLP contour. The required minimum (maximum) length of the contour is $100 \mathrm{~km}(6,750 \mathrm{~km})$. Cyclones over high mountains (i.e., where the 20CR orography exceeds $1,500 \mathrm{~m}$ a.s.l.) are discarded due to the significant extrapolation that is necessary for the calculation of MSLP in these regions. The output of the cyclone identification algorithm is a binary field for each time step indicating the presence of surface cyclones at each grid point. Seasonal averages of cyclone frequency are computed for all DJFM seasons in 1872-2008 and for each of the 20CR ensemble members in the following way: for each 20CR ensemble member, the binary fields of cyclone presence are first aggregated to monthly cyclone frequency fields, which correspond at every location to the percentage of time steps that the grid point is located within a cyclone. Based on these monthly cyclone frequency fields, seasonal averages are computed for all DJFM seasons and for each of the 20CR ensemble members.

\section{Results}

\subsection{Synoptic time scale}

The large-scale meteorological conditions and the SST distribution associated with the ten strongest hazardous wind events in Switzerland are investigated. In this section, large-scale meteorological conditions are analysed based on atmospheric fields at 6-hourly intervals from the $20 \mathrm{CR}$ ensemble dataset at the time when the top ten hazardous wind events in Switzerland occurred; the SST fields from the HadISST dataset which are only available at a monthly resolution are an exception.

The events are selected based on the 20CR ensemble mean time series of 6-hourly WLP for the Switzerland grid cells from 1871 to 2008 during DJFM (Table 1). The list includes recent, well-known destructive winter storms like "Vivian" (February 1990; Schüepp et al. 1994), "Wiebke" (March 1990), "Lothar" (December 1999; Wernli et al. 2002), and "Kyrill" (January 2007; Fink et al. 2009). The list also contains intense historic events, such as a storm in March 1876 described by Scott (1877).

Figure 1a shows cyclone frequencies over Europe during the top ten winter WLP events in Switzerland. The computation of the cyclone frequencies shown in Fig. 1a was different from the computation of seasonal cyclone frequency averages described in Sect. 3.2. For each of the ten events, we first computed the ensemble mean cyclone field. Then, we calculated the composite mean of the ten ensemble mean cyclone fields. From this composite the local climatological mean DJFM cyclone frequency for 1872-2008 was subsequently subtracted.

The top ten hazardous wind events in Switzerland were associated with a high surface cyclone frequency to the

Table 1 The ten most extreme 6-hourly WLP events in Switzerland for the period 1871-2008 (only DJFM) based on the 20CR ensemble mean

\begin{tabular}{lrrrl}
\hline Rank & Year & Month & Day & Storm name and/or reference \\
\hline 1 & 1990 & 3 & 1 & "Wiebke" \\
2 & 1999 & 12 & 26 & "Lothar" (Wernli et al. 2002) \\
3 & 1990 & 2 & 27 & "Vivian" (Schüepp et al. 1994) \\
4 & 1916 & 2 & 16 & listed in Lamb (1991) \\
5 & 1876 & 3 & 12 & Scott (1877) \\
6 & 2003 & 1 & 2 & "Calvann" \\
7 & 2007 & 1 & 18 & "Kyrill" (Fink et al. 2009) \\
8 & 1916 & 2 & 15 & listed in Lamb (1991) \\
9 & 1970 & 2 & 13 & - \\
10 & 1912 & 1 & 7 & listed in Lanz-Stauffer and Rommel \\
& & & & (1936) \\
\hline
\end{tabular}

Given is the date of the event as well as the name and/or reference of the associated windstorm 
(a)

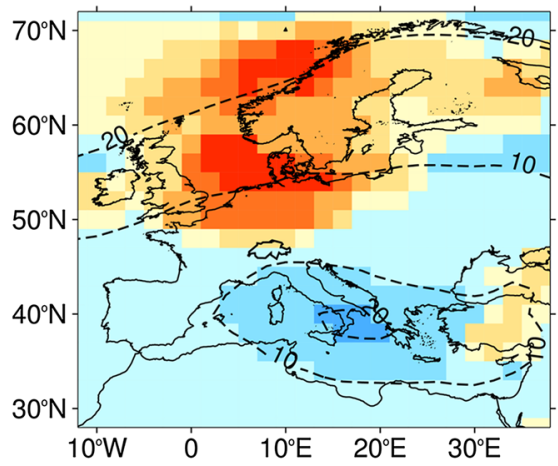

(b)

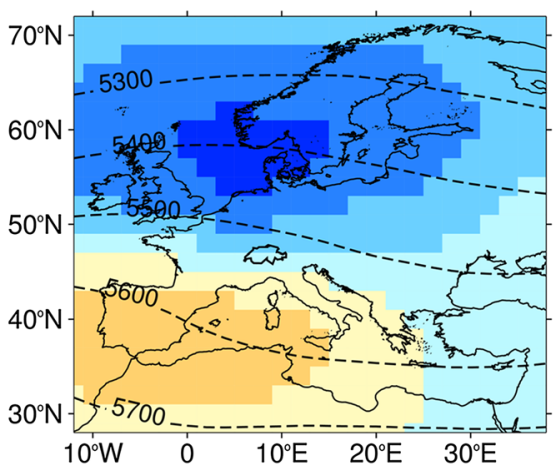

(c)

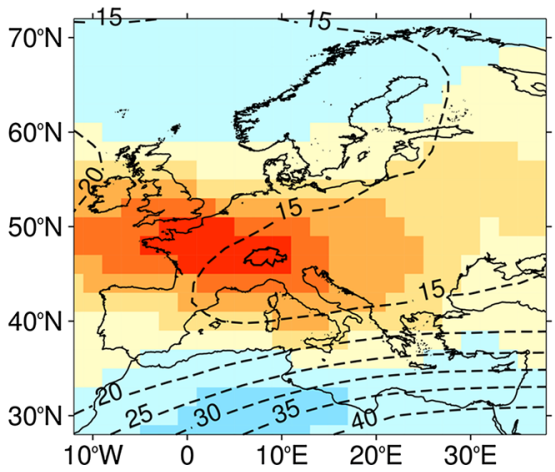

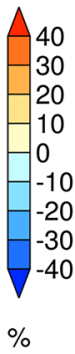

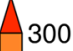

200

$-100$

$-100$

$-200$

$-300$

$\mathrm{m}$ (d)

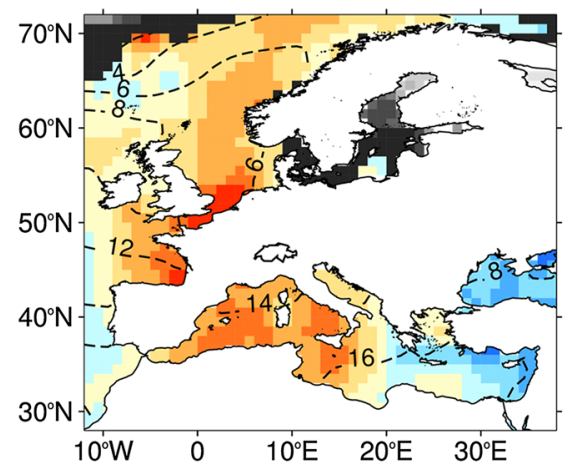

(e)

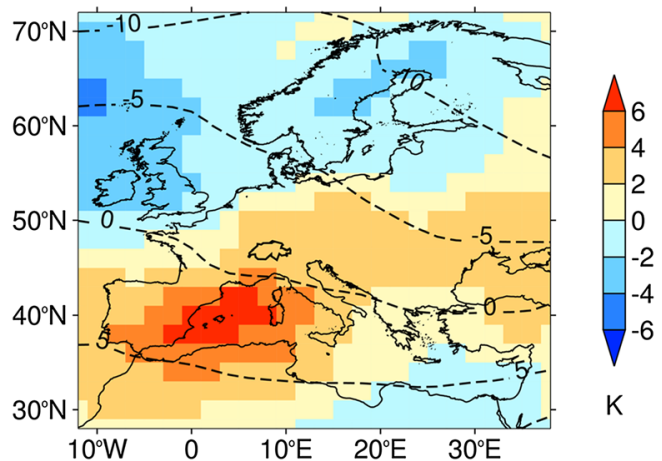

(f)

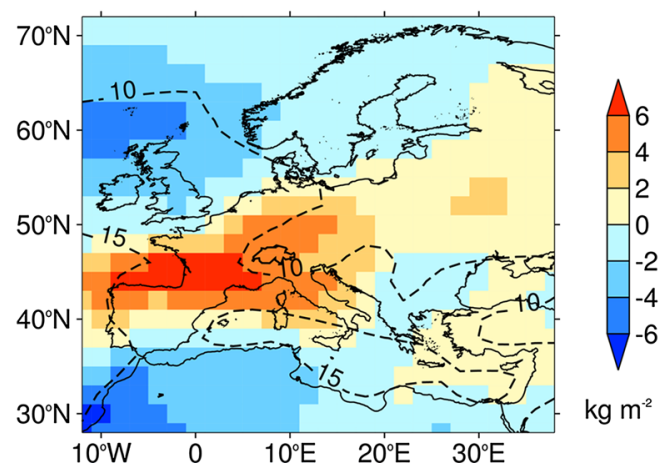

Fig. 1 Composites of the instantaneous a surface cyclone frequency (\%), b 500-hPa geopotential height (m), c 250-hPa wind speed $\left(\mathrm{m} \mathrm{s}^{-1}\right)$, d SST $(\mathrm{K})$, e $850-\mathrm{hPa}$ temperature $(\mathrm{K})$, and f precipitable water $\left(\mathrm{kg} \mathrm{m}^{-2}\right)$ in the European sector during the ten most extreme winter WLP events in Switzerland in the 20CR (Table 1). The colour shade indicates the composite averages normalised by subtracting the respective local climatological DJFM mean for 1872-2008 (dashed contours). For the computation of the SST composites in d, we use monthly SST data, i.e. we consider the SST of the month of the respective event. The grey shade in $\mathbf{d}$ indicates the climatological mean DJFM sea ice coverage for 1872-2008, i.e. the relative fraction of sea ice in each grid cell ranging from $>0 \%$ (dark grey) to $100 \%$ (light grey) in $10 \%$ steps. Switzerland is outlined in each panel

Norwegian Sea (Fig. 1a). This pattern could arise from secondary cyclones forming to the south of primary cyclones or it could be the mix of a southerly and a northerly cyclone track. Visual inspection of the individual cases shows that the southern maximum in cyclone frequency over the North and Baltic Seas is in nine out of ten times not directly attributable to the occurrence of a secondary cyclone south of a primary cyclone. Rather, the two maxima in cyclone frequency are due to the existence of two preferred cyclone pathways.

Overall, the spatial cyclone frequency pattern resembles the pattern of winter cyclone frequency anomalies during 


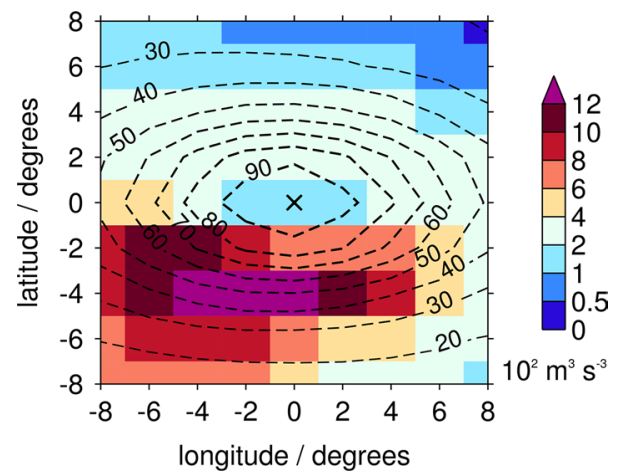

Fig. 2 Cyclone MSLP minima (cross) relative composites of mean cyclone frequency $(\%$; dashed contours $)$ and WLP $\left(10^{2} \mathrm{~m}^{3} \mathrm{~s}^{-3}\right.$; colour shade). The composites are calculated for boxes of $16^{\circ}$ longitude $\times 16^{\circ}$ latitude centred around all cyclone MSLP minima identified in a domain north of Switzerland $\left(4^{\circ} \mathrm{W}-20^{\circ} \mathrm{E}, 48^{\circ} \mathrm{N}-58^{\circ} \mathrm{N}\right)$. They represent the averages over all 6-hourly time steps in 1871-2008 (only DJFM) and all 20CR ensemble members. Note the non-linear colour scale

the positive phase of the NAO (Gulev et al. 2001; see also Figs. 5a, 7b), although the pattern is shifted to the southeast as compared to the pattern associated with the NAO. Indeed, of the ten selected winter storm events in Switzerland, nine occurred during a positive phase of the monthly NAO index.

At mid-tropospheric levels, the geopotential height was considerably decreased to the north of Switzerland, approximately in the region of enhanced surface cyclone frequency, and increased to the southwest of Switzerland (Fig. 1b). This resulted in a substantial southward shift and eastward extension of the extratropical jet stream over the East Atlantic and Western/Central Europe compared to the climatology (Fig. 1c). In the climatological mean the jet is located between $50^{\circ} \mathrm{N}$ and $60^{\circ} \mathrm{N}$ at $10^{\circ} \mathrm{W}$ and even further north at $10^{\circ} \mathrm{E}$ (dashed contours in Fig. 1c). The composite mean jet on the other hand is located between $45^{\circ} \mathrm{N}$ and $50^{\circ} \mathrm{N}$ over the East Atlantic and Central Europe. Concomitantly, the lower-tropospheric meridional temperature gradient was increased between the British Isles and the western Mediterranean (Fig. 1e).

The selected winter storm events were further accompanied by positive anomalies in precipitable water content over large parts of continental Europe (Fig. 1f). This positive anomaly was located approximately $4^{\circ}-6^{\circ}$ north of the strongest positive lower-tropospheric temperature anomaly and at the southern edge of the eastward extended jet.

Finally, the high-wind events in Switzerland were accompanied by anomalously high SSTs in the East Atlantic adjacent to northern Spain, France, and British Isles, in the North and Norwegian Seas, and in the western/central Mediterranean. Furthermore, the high-wind events were associated with anomalously low SSTs in the eastern Mediterranean and Black Sea (Fig. 1d).

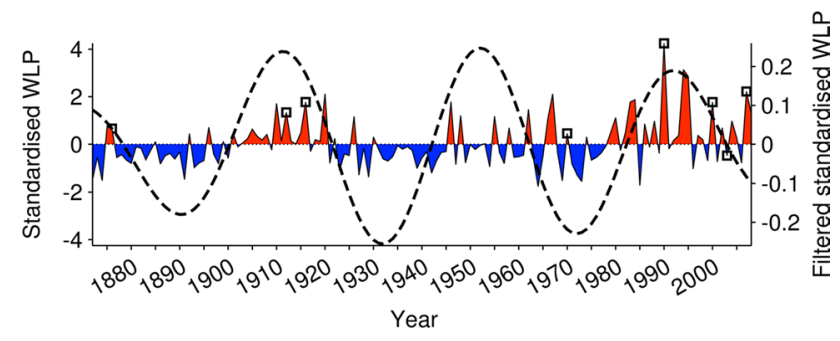

Fig. 3 Standardised 20CR ensemble mean DJFM WLP for Switzerland in 1872-2008 (solid curve and filled areas; left y-axis). Squares mark the winters in which the most extreme WLP events in Switzerland (Table 1) occurred. The dashed curve indicates the 36-47 year variability in the time series of the standardised 20CR ensemble mean DJFM WLP for Switzerland (based on a wavelet analysis technique, following Welker and Martius 2013; right y-axis)

It is interesting to see how the ten most extreme WLP events are related to the seasonal WLP values discussed in the next sections. In total, nine storm events occurred during winters with positive WLP anomalies in Switzerland (Fig. 3). A high winter WLP anomaly can result from a few very strong winter storm events or from frequent but weaker storm events. The interannual variability in DJFM WLP for Switzerland since 1871 was primarily governed by strong winter storm events. The DJFM WLP correlates best with the frequency of events (per DJFM) with high WLP values, i.e. values greater than the seasonal 75 th percentile of all DJFM WLP values (1871-2008, all 20CR ensemble members). The median of the statistically significant correlation coefficients across all ensemble members is 0.95 . By contrast, the correlation of the DJFM WLP with the frequency of events with low WLP values (i.e., values greater than $0 \mathrm{~m}^{3} \mathrm{~s}^{-3}$ and less than or equal to the seasonal 25th percentile) is weak, with an ensemble median correlation coefficient of 0.23 .

\subsection{Interannual time scale}

The winter WLP time series for Switzerland exhibits pronounced year-to-year variability (Fig. 3). The aim of this section is to establish a link between the interannual winter WLP variability and the large-scale atmospheric and SST environment in the NA and European sectors, and to examine the relationship with important teleconnection patterns over the NA and Eurasia. In this study, the winter-to-winter variability is referred to as interannual variability.

\subsubsection{Large-scale atmospheric and SST environment}

The time series of the standardised 20CR ensemble mean winter WLP for Switzerland in 1872-2008 serves as basis for identifying winter seasons with anomalously low WLP (denoted WLP-; marked in blue in Fig. 3) and 


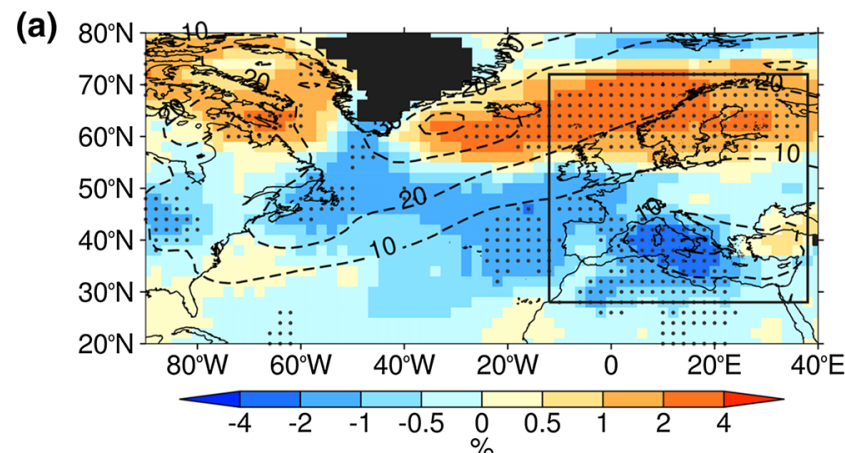

(b)

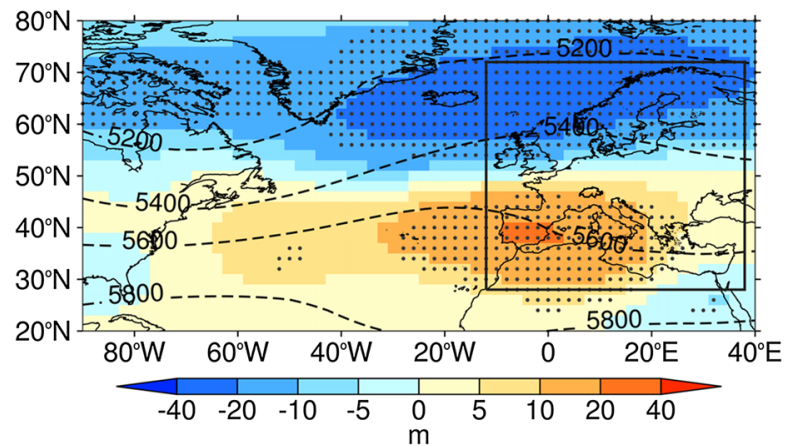

(c)

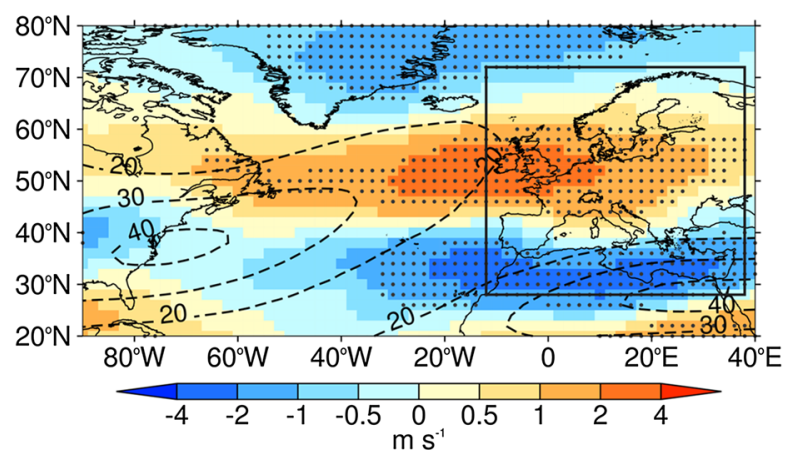

Fig. 4 Differences between composites for WLP+ winters and composites for WLP - winters (i.e., WLP+-WLP-) of a mean DJFM surface cyclone frequency (\%; dark grey grid cells show regions where the 20CR orography exceeds $1500 \mathrm{~m}$ a.s.1.), b mean DJFM 500-hPa geopotential height (m), c mean DJFM 250-hPa wind speed $\left(\mathrm{m} \mathrm{s}^{-1}\right)$, d mean DJFM SST (K), e mean DJFM 850-hPa temperature $(\mathrm{K})$, and $\mathbf{f}$ mean DJFM precipitable water $\left(\mathrm{kg} \mathrm{m}^{-2}\right)$ in the NA and European sectors for 1872-2008 (colour shade). Note the nonlinear colour scales. Grid boxes are marked with grey dots where the samples for WLP+ winters and the samples for WLP- winters have

anomalously high WLP (denoted WLP+; marked red). We then compute differences between composites for WLP+ winters and composites for WLP- winters for the same atmospheric and oceanic variables as discussed above (Fig. 4).

The mid-tropospheric flow during WLP+ winters was characterised by a positive geopotential height anomaly to the south/southwest of Switzerland and a negative geopotential height anomaly to the north, resulting in an anomalously strong meridional mid-tropospheric (d)

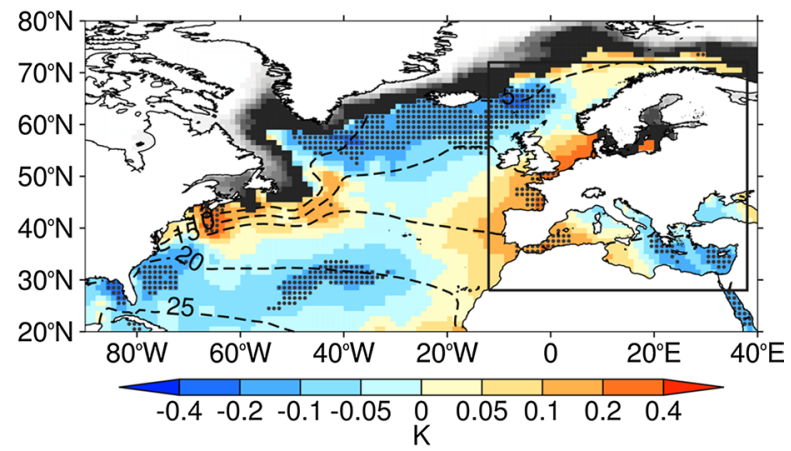

(e)

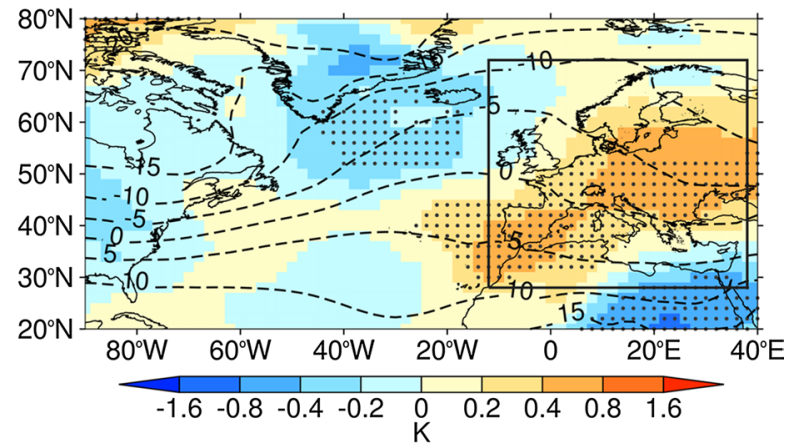

(f)

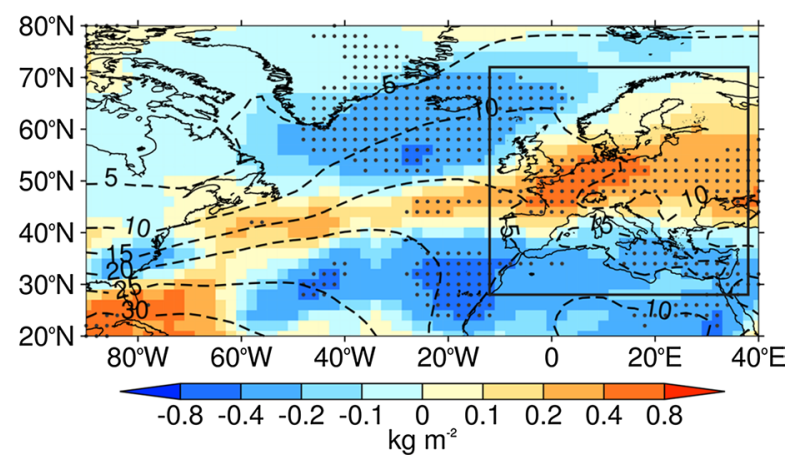

significantly different distribution means at the $5 \%$ significance level, according to a Wilcoxon rank-sum test (e.g., Wilks 2006). Dashed contour lines give the climatological mean for DJFM and 1872-2008: cyclone frequency in $\%, 500-\mathrm{hPa}$ geopotential height in $\mathrm{m}, 250-\mathrm{hPa}$ wind speed in $\mathrm{m} \mathrm{s}^{-1}$, SST and $850-\mathrm{hPa}$ temperature in ${ }^{\circ} \mathrm{C}$, and precipitable water in $\mathrm{kg} \mathrm{m}^{-2}$. The grey shade in $\mathbf{d}$ indicates the climatological mean DJFM sea ice coverage for 1872-2008, i.e. the relative fraction of sea ice in each grid box ranging from $>0 \%$ (dark grey) to $100 \%$ (light grey) in $10 \%$ steps. The location of the European sector (square) and Switzerland are marked in each panel

geopotential gradient over the East Atlantic and Western/ Central Europe (Fig. 4b). At the same time, the upper-level jet stream extended eastward into Central Europe during WLP+ winters (Fig. 4c). At the surface, the cyclone frequency decreased to the south of Switzerland and increased to the north during WLP+ winters (Fig. 4a). The increased cyclone frequency to the north of Switzerland during WLP+ winters was further associated with decreased mean DJFM cyclone centre MSLP (not shown). The cyclone frequency maximum over the North and Baltic Seas that 

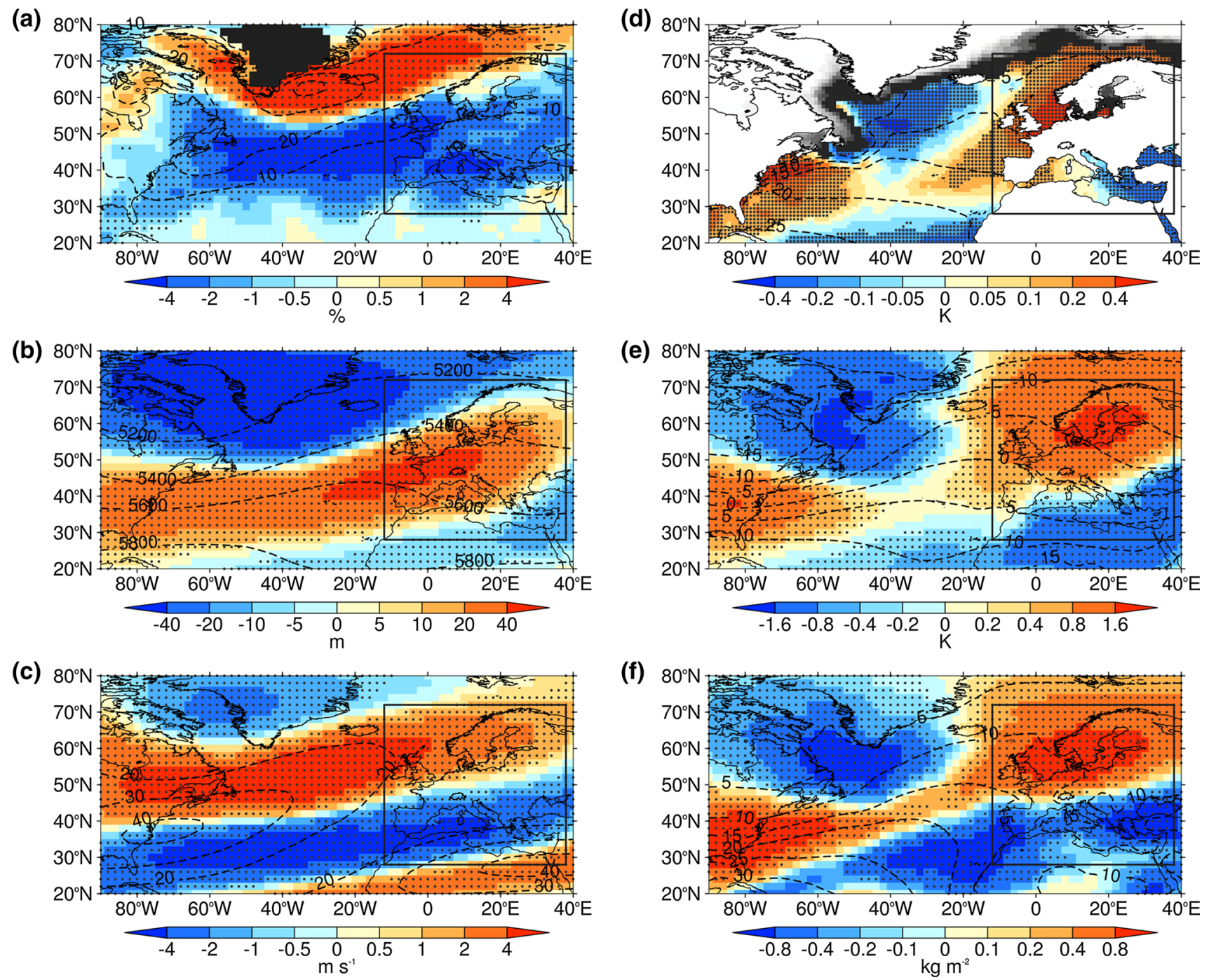

Fig. 5 Analogous to Fig. 4, but shown here are differences between composites for $\mathrm{NAO}+$ winters and composites for $\mathrm{NAO}-$ winters (i.e., NAO+-NAO-) of mean DJFM a surface cyclone frequency,

shows up in the composite for the ten strongest hazardous wind events in Switzerland (Fig. 1a) is not present in the composite for the interannual time scale (Fig. 4a).

WLP+ winters were associated with an increased meridional gradient in lower-tropospheric temperature southwest of the British Isles, and hence increased baroclinicity in this region (Fig. 4e). In addition, lower-tropospheric temperatures were higher over Switzerland and large parts of continental Europe and the adjacent seas, and lower over Greenland/northern NA and Northeast Africa/Arabian Peninsula. High WLP winters were associated with positive precipitable water anomalies over Switzerland and large parts of Europe (Fig. 4f). Hence, "stormy" winters in Switzerland were not only characterised by above-average lower-tropospheric temperatures in Switzerland, but they were also anomalously "wet".

b 500-hPa geopotential height, c 250-hPa wind speed, d SST, e 850$\mathrm{hPa}$ temperature, and $\mathbf{f}$ precipitable water in the NA and European sectors for 1872-2008

High WLP winters were associated with anomalously high SSTs along the east coast of Canada (a region characterised by climatologically strong SST gradients), in the East Atlantic, and in the western Mediterranean. Negative SST anomalies were present in the northern NA, the subtropical NA, and in the eastern Mediterranean and the Red Sea (Fig. 4d). As a consequence, meridional SST gradients were slightly stronger than normal southwest of the British Isles.

In conclusion, similar large-scale atmospheric and oceanic conditions were conducive to hazardous wind speeds in Switzerland on both synoptic and interannual time scales (Figs. 1, 4). The corresponding atmospheric and SST patterns resemble a NAO-like pattern displaced to the southeast. It is therefore interesting to investigate the link between the NAO and the WLP in more detail. 


\subsubsection{Link to teleconnection patterns over the NA and Eurasia}

The atmospheric flow and SST anomalies discussed in the previous section are first compared to the winter NAO pattern in more detail. For this comparison, it is important to look into both the temporal correlation of the NAO and WLP indices and into the associated spatial patterns. To this end, differences between the composites for winters with positive station-based NAO indices (NAO+) and composites for winters with negative NAO indices (NAO-) are computed for the period 1872-2008 (Fig. 5).

Overall, the winter NAO composites are similar to the winter WLP composites for Switzerland (Fig. 4) with three important exceptions: (1) the differences between the NAO+ and NAO - composites are larger in amplitude and the statistically significant areas are spatially more extended as compared to the WLP difference patterns, (2) the NAO anomaly maxima and minima are in general located northwest of the WLP anomaly maxima and minima, and (3) the jet is more tilted and located further north in the NAO difference patterns.

The temporal correlation of the NAO with WLP is investigated next. The correlation coefficients between the time series of the winter WLP for Switzerland for the different 20CR ensemble members and the time series of the stationbased winter NAO index are relatively low (Fig. 6a), with an ensemble median correlation of 0.33 for the whole 20CR period. The spread between individual ensemble members is a measure of the uncertainty. The correlation between the winter WLP for Switzerland and the station-based winter NAO index is higher for the period 1951-2008 (ensemble median $\mathrm{R}=0.46$ ), and the RPCA-based mean winter NAO index correlation is higher yet (ensemble median $\mathrm{R}=0.5$ ) (Table 2). The correlations show an increasing tendency from low values $(\mathrm{R}<0.2)$ in the $1960 \mathrm{~s} / 1970$ s to high values in the 1980s/1990s $(\mathrm{R}>0.6)$.

The ensemble median correlation with the mean winter EA index is 0.31 for 1951-2008 (Table 2). The correlations for the EA were lower than the correlations for the NAO most of the time and showed a similar increasing tendency since the 1960s/1970s (Fig. 6b).

The question arises as to whether, in addition to the $\mathrm{NAO}$ and the EA, teleconnection patterns over Eurasia are suitable to better explain the interannual variability. Candidates are the EA/WR and SCA, both of which affect the position and the strength of the jet over Europe (Fig. 7). To understand the connection between these low-frequency patterns of variability and the WLP in Switzerland on a process basis, their link to the surface cyclone frequency over the NA and European sectors is investigated. The spatial pattern of the temporal correlations between the interannual variability of the winter WLP in Switzerland and
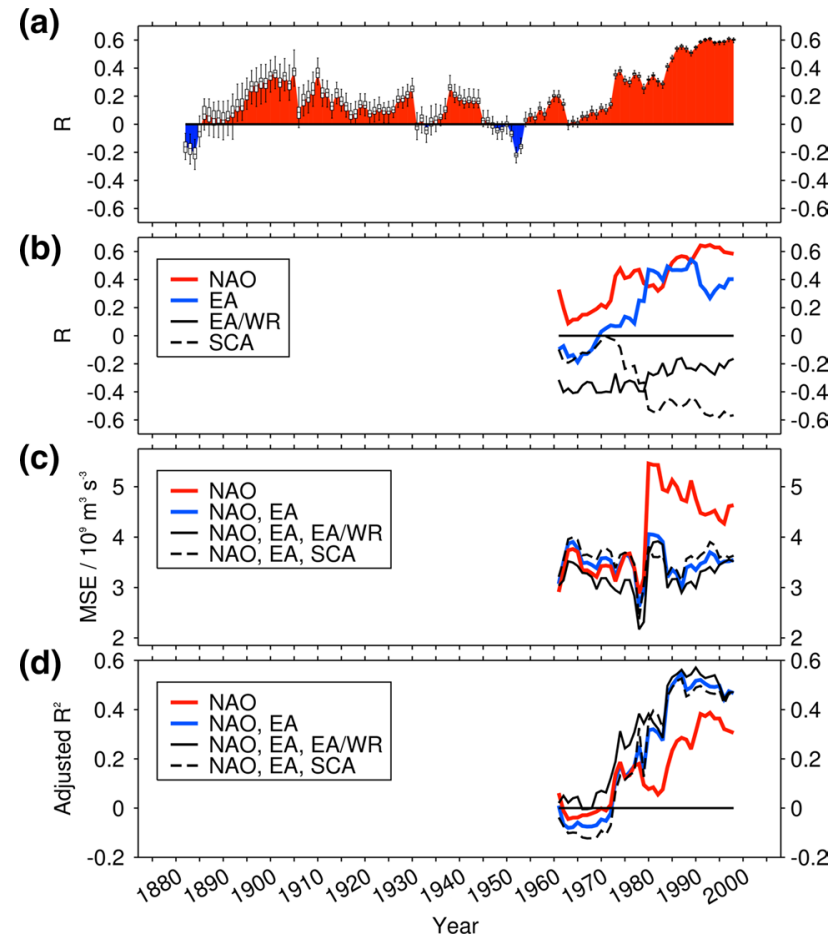

Fig. 6 a Time series of the correlation coefficients between the 20CR ensemble DJFM WLP for Switzerland and the station-based DJFM NAO index for moving windows of 21 winter seasons in 1872-2008. Box plots give the minimum, lower quartile, median, upper quartile, and maximum of the ensemble distribution. The filled areas denote the ensemble median. $\mathbf{b}$ Median of the distribution of the correlation coefficients between the 20CR ensemble DJFM WLP for Switzerland and the RPCA-based mean DJFM NAO index, EA index, EA/WR index, and SCA index, respectively, for moving 21-year periods in 1951-2008. c-d Evaluation of a linear regression model where the dependent variables are the 20CR ensemble DJFM WLP time series for Switzerland and the explanatory variables are different combinations of the RPCA-based mean DJFM teleconnection pattern indices. Shown are the median of the distribution of MSE $\left(10^{9} \mathrm{~m}^{3} \mathrm{~s}^{-3}\right)$ and adjusted $\mathrm{R}^{2}$ statistics, respectively, for moving windows of 21 winters in 1951-2008

the winter surface cyclone frequency during 1951-2008 is shown in Fig. 7. The NAO cyclone correlation pattern bears the strongest resemblance to the WLP cyclone pattern compared to the correlation patterns for the other mean winter NA and Eurasian teleconnection pattern indices considered here.

A linear regression analysis (e.g., Wilks 2006) is applied to model the relationships between different combinations of RPCA-based mean winter NA and Eurasian teleconnection pattern indices (explanatory variables) and the winter WLP time series for Switzerland (dependent variable). The regression is performed for each ensemble member for moving 21-year periods in 1951-2008. To evaluate the linear regression model, we use the mean squared error (MSE) statistic (Fig. 6c) and the adjusted coefficient of determination (adjusted $\mathrm{R}^{2}$ ) (Fig. 6d), which takes into account the 
Table 2 Median of the distribution of correlation coefficients between the 20CR ensemble DJFM WLP time series for Switzerland and the station-based DJFM NAO index, RPCA-based mean DJFM NAO index, EA index, EA/WR index, and SCA index, respectively

\begin{tabular}{lll}
\hline Index & $\begin{array}{l}\mathrm{R} \text { for 1951- } \\
2008\end{array}$ & $\begin{array}{l}\text { Minimum and maximum R } \\
\text { for moving 21-year periods, } \\
1951-2008\end{array}$ \\
\hline Station-based NAO & 0.46 & $0 ; 0.61$ \\
RPCA-based NAO & 0.5 & $0.09 ; 0.65$ \\
EA & 0.31 & $-0.19 ; 0.54$ \\
EA/WR & -0.2 & $-0.41 ;-0.16$ \\
SCA & -0.42 & $-0.58 ; 0$ \\
\hline
\end{tabular}

All calculations are made either for the entire period 1951-2008 or using a moving window of 21 winter seasons for this period fact that the coefficient of determination increases with the number of explanatory variables included in the model. A small value of the MSE and a high adjusted $\mathrm{R}^{2}$ statistic indicate a suitable model.

When the mean winter NAO index is used as a single regressor, the MSE is relatively stable until the 1970s/1980s. Then, the MSE increases abruptly and decreases more slowly afterwards (Fig. 6c). The MSE of the linear model improves considerably in the period since the 1970 s/1980s if the mean winter EA index is used as an additional regressor. Combinations of three explanatory variables in the linear model-where the first regressor is the mean winter NAO index, the second is the mean winter EA index, and the third is either the mean winter

(a)

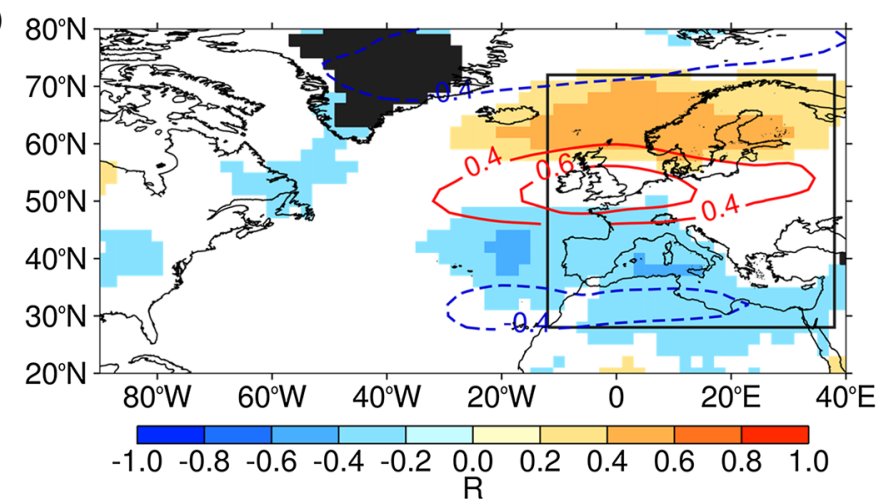

(b)

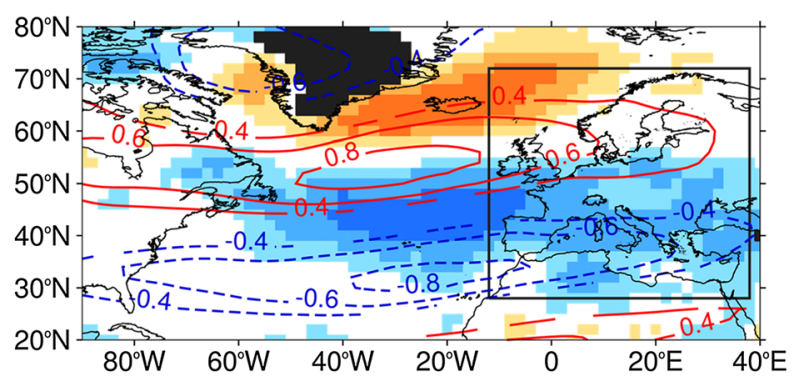

(c)

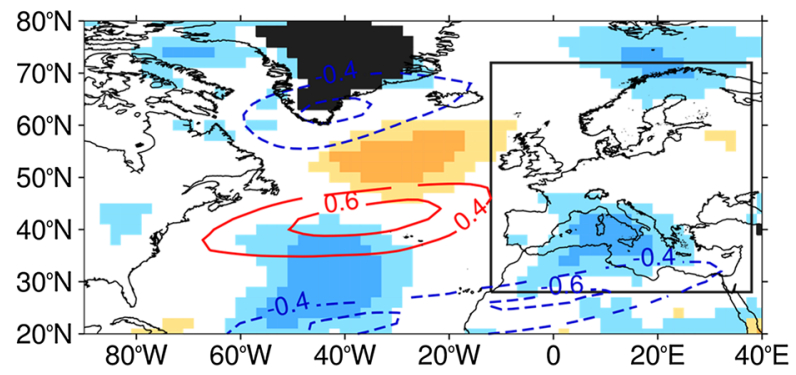

Fig. 7 a Spatial patterns of the ensemble median temporal correlation (1951-2008) between the mean DJFM surface cyclone frequency at each grid cell in the NA and European sectors and the DJFM WLP for Switzerland (colour shade). Only statistically significant correlations at the $5 \%$ significance level are plotted, and only for regions where the 20CR orography is below $1500 \mathrm{~m}$ a.s.l. Contour lines indicate statistically significant correlations (ensemble median $|R| \geq 0.4$ ) (d)

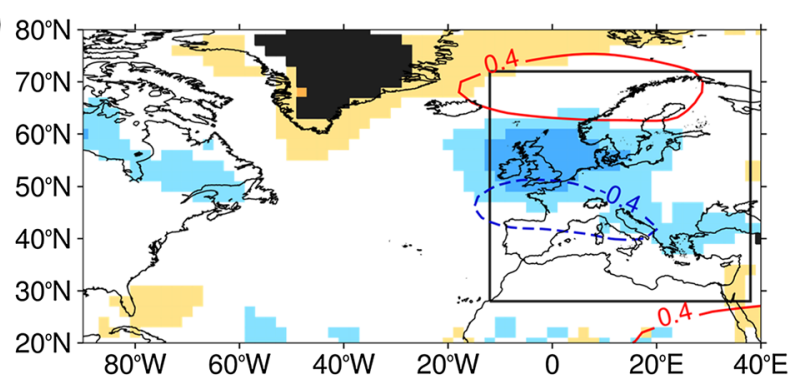

(e)

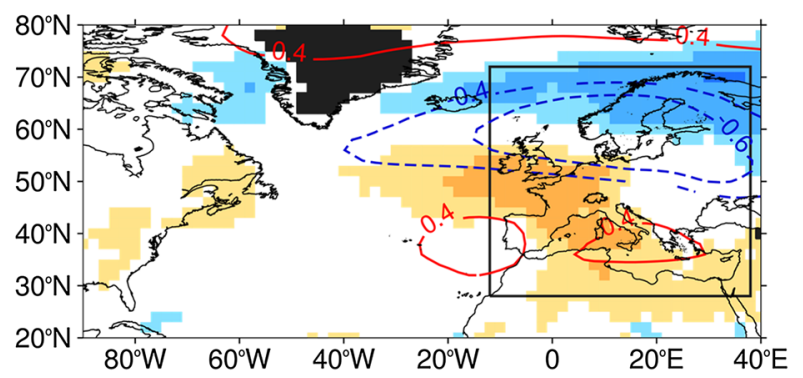

between the DJFM WLP for Switzerland and the mean DJFM 250hPa wind speed. Analogously, the other panels show the corresponding spatial patterns of temporal correlations of the mean DJFM surface cyclone frequency (250-hPa wind speed) with the RPCA-based mean DJFM b NAO index, c EA index, d EA/WR index, and e SCA index. The location of the European sector (square) and Switzerland are marked in each panel 
EA/WR index or the mean winter SCA index-result in a marginal improvement of the MSE. Overall, the NAO-EAEA/WR combination gives the best results. Similar findings are obtained if the adjusted $R^{2}$ statistic is used to evaluate the quality of the model (Fig. 6d). As with the MSE, the adjusted $\mathrm{R}^{2}$ improves considerably in the period since roughly the 1970s/1980s if the EA is used as a regressor in addition to the NAO.

In summary, the correlation of the NAO and the EA with the interannual winter WLP variability in Switzerland varied considerably over time. Together, the NAO and the EA explain $26 \%$ of the year-to-year variability in winter WLP in Switzerland for the period 1951-2008 and up to $55 \%$ for moving 21-year periods in 1951-2008. Incorporating additional teleconnection patterns over Eurasia into the regression model increases the explained variance only marginally.

\subsection{Decadal time scale}

The winter WLP time series for Switzerland exhibits not only pronounced year-to-year variability but also statistically significant variability at decadal time scales, namely at periodicities of approximately $36-47$ years (Welker and Martius 2013). We use the wavelet transform as a bandpass filter to isolate decadal-scale variations in the time series of the standardised 20CR ensemble mean winter WLP for Switzerland from 1872 to 2008 (see Torrence and Compo 1998 for technical details). This wavelet-filtered time series (dashed curve in Fig. 3) serves as a basis for identifying decades of low and high winter WLP in Switzerland. Note that the absolute amplitude of the bandpass-filtered WLP time series is affected by the zero padding at the beginning and end of the time series during the filtering procedure. The sign of the standardised time series, however, is robust and winters with negative (positive) values in the bandpass-filtered, standardised time series are classified as low (high) WLP sub-periods. The low WLP sub-periods are 1879-1900, 1922-1942, 1963-1982, and 2003-2008. The high WLP sub-periods are 1872-1878, 1901-1921, 1943-1962, and 1983-2002. We then compute composites of atmospheric and oceanic variables for the two phases of the decadal WLP variability, subtract the negative from the positive composite, and determine the statistically significant differences (Fig. 8).

The resulting spatial patterns for the decadal-scale winter WLP variability in Switzerland resemble the winter NAO variability patterns (Fig. 5) more strongly than the patterns for the interannual winter WLP variability in Switzerland (Fig. 4). For example, the SST anomaly patterns are very similar to the SST anomaly patterns associated with the winter NAO variability. However, compared to the winter NAO variability patterns, the decadal winter WLP variability patterns are also displaced eastward and equatorward. As is the case on interannual time scales, the jet over Western/Central Europe is located further south and is more zonal in the decadal winter WLP variability composites than the winter NAO variability composites. During high WLP sub-periods, Switzerland was located at the southern edge of the southward-displaced jet.

\section{Discussion and conclusions}

This study focuses on the link between the variability in hazardous winter winds in Switzerland since the late nineteenth century and the large-scale atmospheric flow conditions and SST environment, respectively, in the NA basin. Using the 20CR, this link is investigated for the ten strongest wind events in Switzerland and for both the interannual and decadal-scale variability of hazardous winds. The important role of the strength and the position of the extratropical jet in the formation of strong winter storms that affect Switzerland was discussed in the introduction, as were the roles of surface cyclone positions and SST anomalies in the NA. The most extreme winter WLP events in Switzerland in the 20CR dataset were accompanied by flow conditions similar to those discussed in previous studies, namely an increased (decreased) cyclone frequency to the north (south) of Switzerland at the surface, and at upper-tropospheric levels by a southward shifted, eastward extended, and zonally oriented extratropical jet stream over the East Atlantic and Western/Central Europe. The variability in winter WLP for Switzerland on interannual scales was associated with a large-scale atmospheric and SST spatial pattern similar to a southeastward-displaced NAOlike pattern with a zonally oriented and eastward-extended jet. The spatial pattern for the decadal-scale variability of winter WLP in Switzerland at periodicities of 36-47 years is overall closer to the winter NAO variability pattern. This is in agreement with Welker and Martius (2013), who found that the winter WLP variability in Switzerland was positively correlated with the variability in the winter NAO index at periodicities of 36-47 years, even though the strength of the co-variability varied over time.

We further assess the link between WLP variability and teleconnection patterns over the NA and over Eurasia. We expect a link to the NAO and the EA because the occurrence of high winds in Switzerland is associated with the position of the extratropical jet stream (Mahlstein et al. 2012), which is in turn affected by the NAO and the EA (Woollings et al. 2010). Together, the NAO and the EA explain $26 \%$ (up to $55 \%$ ) of the interannual variability in hazardous winter winds in Switzerland for the period 1951-2008 (for moving windows of 21 winter seasons). Considering additional physically relevant Eurasian 


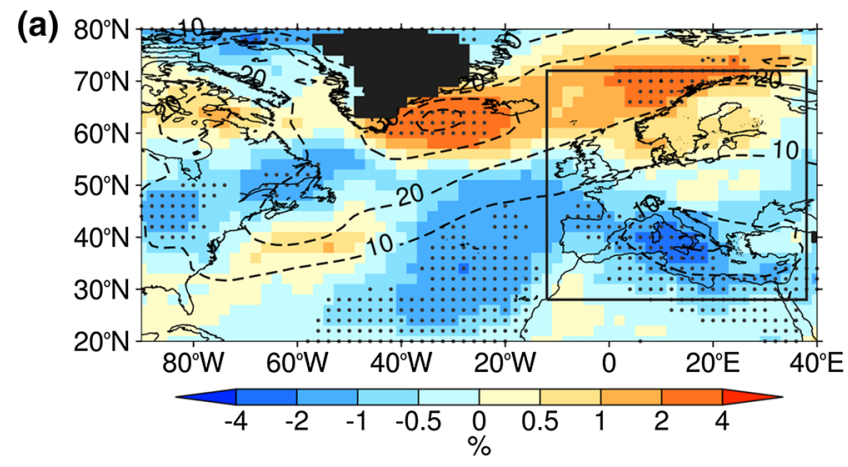

(b)

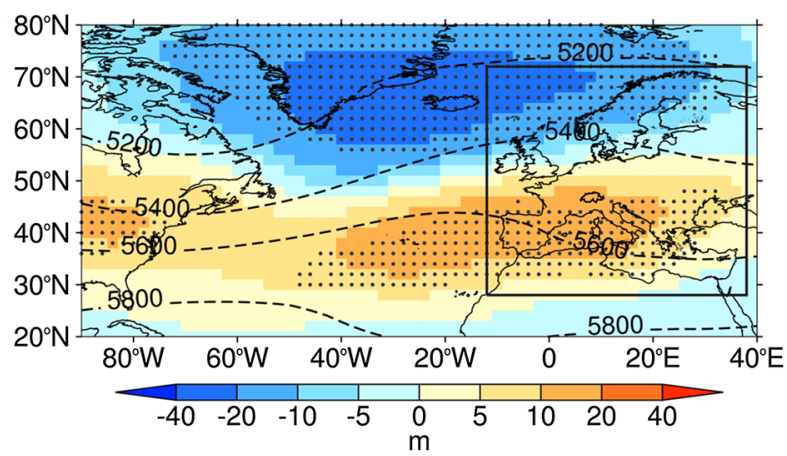

(c)

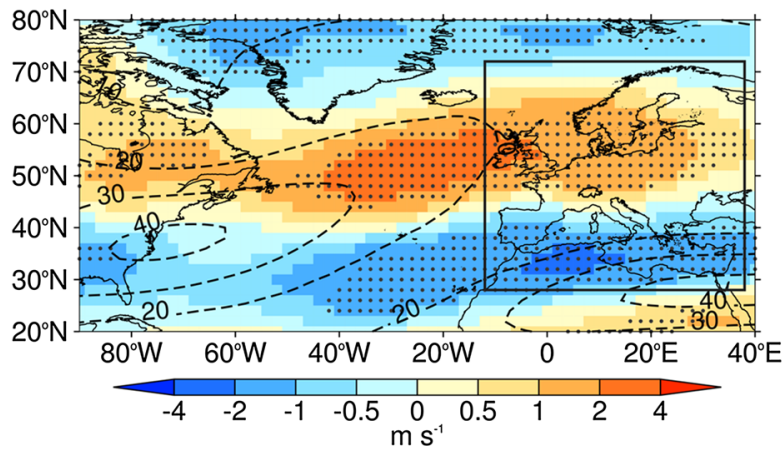

Fig. 8 Analogous to Fig. 4, but shown are differences between the composite averages for low sub-periods and high sub-periods (i.e., high-low) of the decadal-scale winter WLP variability in Switzerland (see text for definition) of mean DJFM a surface cyclone frequency,

teleconnection patterns in the regression model, i.e. the EA/WR and SCA, only marginally increases the explained variability.

The correlation between the interannual variability in winter WLP for Switzerland and the winter NAO and EA was non-stationary and care therefore has to be taken in drawing conclusions from recent data. Indeed, in the more recent past, correlations between the winter WLP in Switzerland and the NA teleconnection patterns increased considerably. The WLP was also very high during this period, reaching the highest values during the entire 20CR time period. In recent decades, the NAO has exhibited a pronounced positive trend, moving from mainly low values in the 1960s to predominantly high values in the 1990s (Hurrell 1995). This trend in the NAO index was accompanied
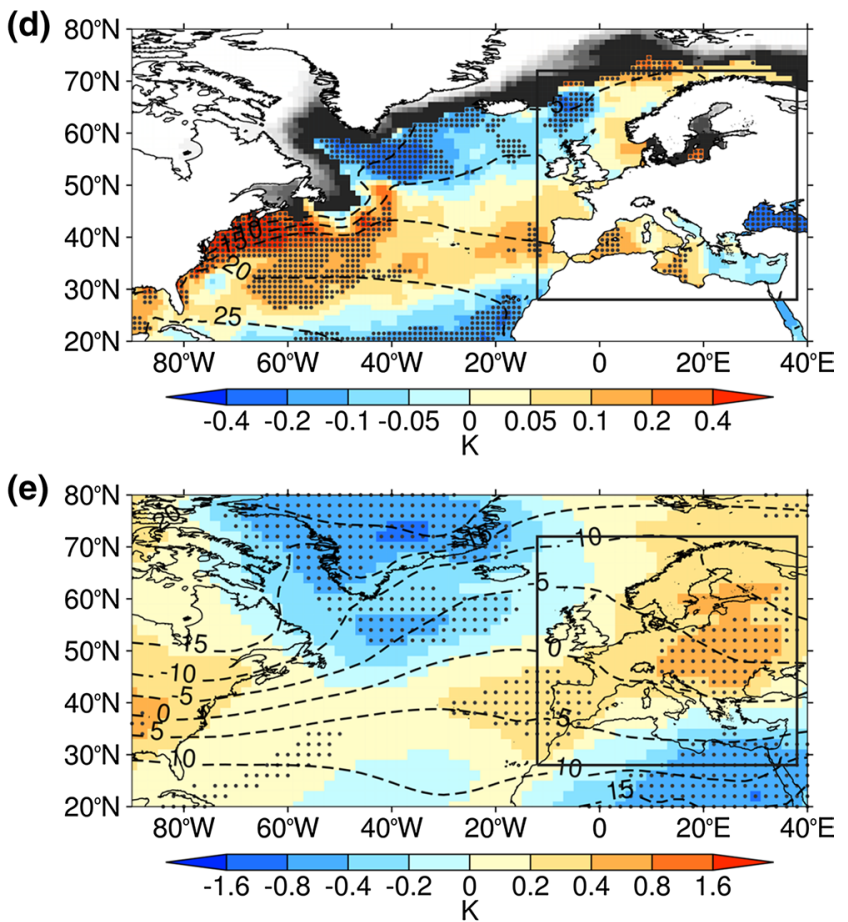

(f)

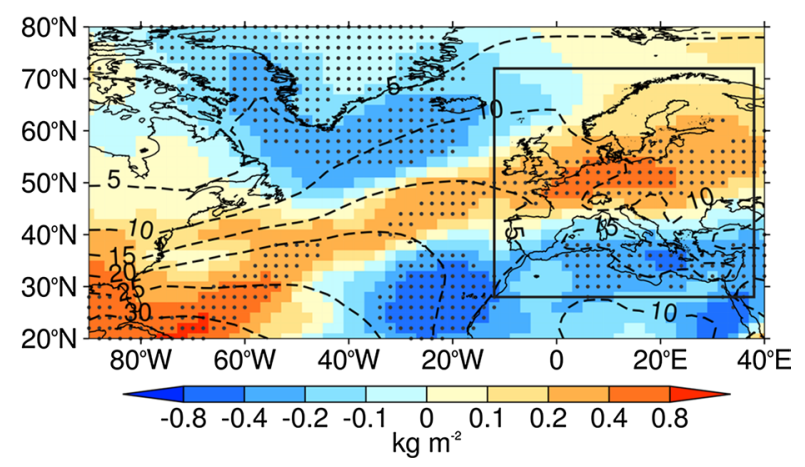

b 500-hPa geopotential height, c 250-hPa wind speed, d SST, e 850$\mathrm{hPa}$ temperature, and $\mathbf{f}$ precipitable water in the NA and European sectors in 1872-2008

by a distinct eastward shift of the northern centre of action of the NAO (Hilmer and Jung 2000). This eastward shift was unprecedented during the twentieth century and resulted in distinct changes in the interannual climate variability associated with the NAO (Jung et al. 2003).

On the decadal time scale, Welker and Martius (2013) found a phase shift of approximately 5 years, with the winter NAO index variability leading the winter WLP variability in Switzerland. This indicates that a high winter WLP in Switzerland was generally associated with a positive but decreasing winter NAO index. Hanley and Caballero (2012) came to similar results for synoptic time scales. They found that the most extreme windstorms affecting continental Western Europe typically occurred 2 days after the peak of strong positive anomalies in the NAO. The 
NAO dipole pattern had then moved eastward over Europe and was associated with a deep low-pressure system over Scandinavia. At upper levels, the eastward shift of the NAO pattern was accompanied by a persistent cyclonic Rossby wave breaking event in the north and an anticyclonic wave breaking event in the subtropics. The associated momentum fluxes resulted in an intensified and zonally elongated jet stream over the NA (Hanley and Caballero 2012). On longer timescales, Wang and Magnusdottir (2012) found a very similar synoptic pattern to be responsible for the eastward shift of the NAO. They observed that the eastward shift of the northern node of the NAO during the winters of 1978-1997 was accompanied by a northeastward shift of the region of frequent cyclonic Rossby wave breaking at high latitudes.

In summary, the eastward shift of the NAO pattern during the last decades of the twentieth century might explain the improved correlation between the interannual winter WLP variability in Switzerland and the winter NAO variability. The eastward shift occurs during the transition from the peak positive value of the NAO towards a neutral state of the NAO, which potentially explains the phase shift between the NAO and the WLP on decadal time scales.

The results of this study raise a number of interesting questions that we aim to address in future studies:

1. An anomalously high winter WLP in Switzerland was associated with an increased meridional gradient in SST and lower-tropospheric temperature in the NA sector southwest of the British Isles and thus increased baroclinicity in this region. However, deducing cause and effect is very difficult since the SST anomalies could be generated by changes in Ekman pumping induced by changes in large-scale surface wind stress patterns (e.g., Marshall and Plumb 2008).

2. Diabatic processes can play an important role in the formation and intensification of very intense extratropical cyclones (e.g., Wernli et al. 2002; Fink et al. 2012; Ludwig et al. 2013). The positive SST anomalies in the East Atlantic, as well as the positive moisture anomalies over Western and Central Europe during high WLP winters in Switzerland, have the potential to intensify these diabatic processes. It would be interesting to investigate how important the enhancement of diabatic processes through these positive SST and moisture anomalies was for the intensity of cyclones affecting Switzerland.

3. Closely related to the previous point is the question regarding the source of the positive moisture anomaly over Europe. The positive SST anomalies could contribute to the moisture anomalies. However, the shape of the positive moisture anomaly over Europe during high WLP winters and its co-alignment with the south- ern flank of the jet stream suggests that the moisture anomaly might have formed through large-scale advection from the tropics.

Addressing these questions will require (idealised) experiments with coupled atmosphere-ocean models and moisture source calculations using trajectories.

Acknowledgments We thank two anonymous reviewers for comments which improved the quality of the manuscript. We thank $\mathrm{H}$. Wernli and M. Sprenger for making their cyclone identification algorithm available. Support for the Twentieth Century Reanalysis Project dataset is provided by the U.S. Department of Energy, Office of Science Innovative and Novel Computational Impact on Theory and Experiment (DOE INCITE) program, and Office of Biological and Environmental Research (BER), and by the National Oceanic and Atmospheric Administration Climate Program Office. J. Hurrell's station-based NAO index records are available at http://climatedatag uide.ucar.edu/guidance/hurrell-north-atlantic-oscillation-nao-indexstation-based (last access: December 2012). Monthly RPCA-based NA and Eurasian teleconnection pattern indices from the CPC are available at ftp://cpc.ncep.noaa.gov/wd52dg/data/indices/ (last access: December 2012). Wavelet software was provided by C. Torrence and G. Compo and is available at http://atoc.colorado.edu/research/wavelets/ (last access: March 2012).

\section{References}

Barnston AG, Livezey RE (1987) Classification, seasonality and persistence of low-frequency atmospheric circulation patterns. Mon Weather Rev 115:1083-1126

Compo GP, Whitaker JS, Sardeshmukh PD, Matsui N, Allan RJ, Yin X, Gleason BE, Vose RS, Rutledge G, Bessemoulin P, Brönnimann S, Brunet M, Crouthamel RI, Grant AN, Groisman PY, Jones PD, Kruk MC, Kruger AC, Marshall GJ, Maugeri M, Mok HY, Nordli Ø, Ross TF, Trigo RM, Wang XL, Woodruff SD, Worley SJ (2011) The twentieth century reanalysis project. Q J R Meteor Soc 137:1-28

Donat MG, Leckebusch GC, Pinto JG, Ulbrich U (2010) Examination of wind storms over Central Europe with respect to circulation weather types and NAO phases. Int J Climatol 30:1289-1300

Emanuel K (2005) Increasing destructiveness of tropical cyclones over the past 30 years. Nature 436:686-688

Fink AH, Brücher T, Ermert V, Krüger A, Pinto JG (2009) The European storm Kyrill in January 2007: synoptic evolution, meteorological impacts and some considerations with respect to climate change. Nat Hazards Earth Syst Sci 9:405-423

Fink AH, Pohle S, Pinto JG, Knippertz P (2012) Diagnosing the influence of diabatic processes on the explosive deepening of extratropical cyclones. Geophys Res Lett 39:L07803. doi:10.1029/20 12GL051025

Franzke C, Feldstein SB (2005) The continuum and dynamics of Northern Hemisphere teleconnection patterns. J Atmos Sci 62:3250-3267

Goyette S (2011) Synoptic conditions of extreme windstorms over Switzerland in a changing climate. Clim Dyn 36:845-866

Gulev SK, Zolina O, Grigoriev S (2001) Extratropical cyclone variability in the Northern Hemisphere winter from the NCEP/NCAR reanalysis data. Clim Dyn 17:795-809

Hanley J, Caballero R (2012) The role of large-scale atmospheric flow and Rossby wave breaking in the evolution of extreme windstorms over Europe. Geophys Res Lett 39:L21708. doi:10.1029/ 2012GL053408 
Hilmer M, Jung T (2000) Evidence for a recent change in the link between the North Atlantic Oscillation and Arctic sea ice export. Geophys Res Lett 27:989-992. doi:10.1029/1999GL010944

Hurrell JW (1995) Decadal trends in the North Atlantic Oscillation: regional temperatures and precipitation. Science 269:676-679

Imhof M (2011) Analyse langfristiger Gebäudeschadendaten. Interkantonaler Rückversicherungsverband, Bern

Jung T, Hilmer M, Ruprecht E, Kleppek S, Gulev SK, Zolina O (2003) Characteristics of the recent eastward shift of interannual NAO variability. J Clim 16:3371-3382

Klawa M, Ulbrich U (2003) A model for the estimation of storm losses and the identification of severe winter storms in Germany. Nat Hazards Earth Syst Sci 3:725-732

Lamb HH (1991) Historic Storms of the North Sea, British Isles and Northwest Europe. Cambridge University Press, Cambridge

Lanz-Stauffer H, Rommel C (1936) Elementarschäden und Versicherung. Selbstverlag des Rückversicherungsverbandes, Bern

Ludwig P, Pinto JG, Reyers M, Gray SL (2013) The role of anomalous SST and surface fluxes over the southeastern North Atlantic in the explosive development of windstorm Xynthia. Q J R Meteor Soc. doi:10.1002/qj.2253

Mahlstein I, Martius O, Chevalier C, Ginsbourger D (2012) Changes in the odds of extreme events in the Atlantic basin depending on the position of the extratropical jet. Geophys Res Lett 39:L22805. doi:10.1029/2012GL053993

Marshall J, Plumb RA (2008) Atmosphere, ocean and climate dynamics-an introductory text. Elsevier Academic Press, Burlington

Matulla C, Schöner W, Alexandersson H, von Storch H, Wang XL (2008) European storminess: late nineteenth century to present. Clim Dyn 31:125-130

Nissen KM, Leckebusch GC, Pinto JG, Renggli D, Ulbrich S, Ulbrich U (2010) Cyclones causing wind storms in the Mediterranean: characteristics, trends and links to large-scale patterns. Nat Hazards Earth Syst Sci 10:1379-1391

Pinto JG, Zacharias S, Fink AH, Leckebusch GC, Ulbrich U (2009) Factors contributing to the development of extreme North Atlantic cyclones and their relationship with the NAO. Clim Dyn $32: 711-737$
Raible CC (2007) On the relation between extremes of midlatitude cyclones and the atmospheric circulation using ERA40. Geophys Res Lett 34:L07703. doi:10.1029/2006GL029084

Rayner NA, Parker DE, Horton EB, Folland CK, Alexander LV, Rowell DP, Kent EC, Kaplan A (2003) Global analyses of sea surface temperature, sea ice, and night marine air temperature since the late nineteenth century. J Geophys Res 108:4407

Schüepp M, Schiesser HH, Huntrieser H, Scherrer HU, Schmidtke H (1994) The winterstorm "Vivian" of 27 February 1990: about the meteorological development, wind forces and damage situation in the forests of Switzerland. Theor Appl Climatol 49:183-200

Schwierz C, Köllner-Heck P, Zenklusen Mutter E, Bresch DN, Vidale P-L, Wild M, Schär C (2010) Modelling European winter wind storm losses in current and future climate. Clim Change 101:485-514

Scott RH (1877) On the storm which passed over the south of England, March 12th, 1876. Q J R Meteor Soc 3:159-175

Torrence C, Compo GP (1998) A practical guide to wavelet analysis. Bull Am Meteorol Soc 79:61-78

Wang Y-H, Magnusdottir G (2012) The shift of the northern node of the NAO and cyclonic Rossby wave breaking. J Clim 25:7973-7982

Welker C, Martius O (2013) Decadal-scale variability in hazardous winds in northern Switzerland since end of the 19th century. Atmos Sci Lett. doi:10.1002/as12.467

Wernli H, Schwierz C (2006) Surface cyclones in the ERA-40 dataset (1958-2001). Part I: novel identification method and global climatology. J Atmos Sci 63:2486-2507

Wernli H, Dirren S, Liniger MA, Zillig M (2002) Dynamical aspects of the life cycle of the winter storm 'Lothar' (24-26 December 1999). Q J R Meteor Soc 128:405-429

Wilks DS (2006) Statistical methods in the atmospheric sciences. Elsevier Academic Press, Burlington

Woollings T, Hannachi A, Hoskins B (2010) Variability of the North Atlantic eddy driven jet stream. Q J R Meteor Soc 136:856-868 